\title{
Intensity-modulated radiation therapy (IMRT) versus 3-dimensional conformal radiation therapy (3D-CRT) for head and neck cancer: cost-effectiveness analysis
}

(10) Gustavo Nader Marta, MD, PhD'

Eduardo Weltman, MD, PhD

Robson Ferrigno, MD, $P h D^{3}$

\begin{abstract}
1. Department of Radiation Oncology; Hospital Sírio-Libanês and Instituto do Câncer de Estado de São Paulo (ICESP) - Faculdade de Medicina da Universidade de São Paulo (FMUSP); São Paulo, Brasil. 2. Department of Radiation Oncology; Hospital Israelita Albert Einstein, São Paulo, Brasil; Faculdade de Medicina da Universidade de São Paulo (FMUSP) Discipline of Radiation Oncology, São Paulo, Brasil. 3. Department of Radiation Oncology; Hospital Beneficiência Portuguesa, São Paulo, Brasil.
\end{abstract}

http://dx.doi.org/10.1590/1806-9282.64.04.318

\section{SUMMARY}

BACKGROUND: A cost-effectiveness analysis of IMRT compared to 3D-CRT for head and neck cancer patients (HNCPS) was conducted in the Brazilian Public Health System.

METHODS: A Markov model was used to simulate radiation therapy-induced dysphagia and xerostomia in HNCPS. Data from the PARSPORT trial and the quality-of-life study were used as parameters. The incremental cost-effectiveness ratio (ICER) and cost per quality-adjusted life-year (QALY) gained were calculated.

RESULTS: At 2 years, IMRT was associated with an incremental benefit of 0.16 QALYs gained per person, resulting in an ICER of BRL 31,579 per QALY gained. IMRT was considered cost-effective when using the guideline proposed by the World Health Organization (WHO) of three times the national gross domestic product (GDP) per capita (BRL 72,195). Regarding life expectancy (15 years), the incremental benefit of IMRT was 1.16 QALYs gained per person, with an ICER of BRL 4,341. IMRT was also cost-effective using the WHO definition, which states that the maximum cost is equal to the GDP per capita (BRL 24,065).

CONCLUSIONS: IMRT was considered cost-effective from the perspective of the Brazilian public health system.

KEYWORDS: Head and neck neoplasms. Radiotherapy, intensity-modulated. Radiotherapy, conformal. Cost-benefit analysis.

\section{INTRODUCTION}

The capacity to accurately deliver high doses of radiation to a tumor while reducing the radiation exposure to the neighboring normal tissues has been made possible by the intensity-modulated radiation therapy (IMRT) technique ${ }^{1,2}$. The advantages of IMRT over 3-dimensional conformal radiation therapy (3D-CRT) include its steeper dose gradient and a more conformal dose delivery ${ }^{3,4}$.

IMRT has been widely used in recent years for the treatment of locally advanced head and neck cancer patients $(\mathrm{HNCPs})^{5}$. Several randomized trials ${ }^{6-10}$ and a meta-analysis ${ }^{11}$ have confirmed that IMRT has substantial benefits not only related to dosimetric issues but also in terms of reduced treatment toxicity for HNCPs. Specifically, IMRT is associated with less severe xerostomia, dysphagia, acute and late hearing loss, cervical fibrosis and trismus, but it does not compromise local tumor control or overall survival ${ }^{12,13}$.

However, IMRT is challenging due to the complexi-

DATE OF SUBMISSION: 09-Jun-2017

DATE OF ACCEPTANCE: 26-Jun-2017

CORRESPONDING AUTHOR: Gustavo Nader Marta

Hospital Sírio-Libanês - Radiation Oncology Department

Rua Dona Adma Jafet 91. São Paulo-SP - Brasil - CEP 01308-050

Tel: (+55 11) 3394-5367 - FAX: (+55 11) 3155-0983

E-mail:gnmarta@uol.com.br

eduardo.weltman@einstein.br rferrigno@uol.com.br 
ty of planning. To ensure secure and satisfactory treatment, additional clinician effort is required to delineate all volumes of interest, and extra time is needed for physicists to provide the more complex quality assurance associated with this method, which increases the apparent incremental costs of IMRT ${ }^{14,15}$.

While IMRT is currently the standard technique for treatment of locally advanced HNCPs, a comparison of the health economic value of IMRT versus 3D-CRT is needed to determine the economic feasibility of this practice, especially in developing countries ${ }^{16}$. The aim of this study, therefore, was to perform a cost-effectiveness analysis of IMRT compared to 3D-CRT for HNCPs in the Brazilian Public Health System.

\section{METHODS AND MATERIALS}

\section{Model structure}

The perspective of the Brazilian Public Health System was considered. The model structures adopted were similar to that reported by Kohler et al. ${ }^{17}$. A Markov model was used to assess the radiation toxicities (xerostomia and dysphagia) that developed in HNCPs treated with IMRT or 3D-CRT (Figure 1). The starting patient age for our hypothetical cohort was 57 years (corresponding to the mean age of PARSPORT trial ${ }^{8}$ patients). The model calculated quality-adjusted life-years (QALYs) and costs associated with the IMRT and 3D-CRT techniques.

The model is based on six states of health, including four combinations of different toxicities (dysphagia and xerostomia), loss to follow-up and death (Figure 1).

Some basic assumptions were formulated for the analyses in this study:

- Xerostomia and dysphagia were dichotomized into severe (grade $\geq 2$ ) and mild (grade 0-1), based on the PARSPORT trial ${ }^{8}$, creating four states of health (1 - low xerostomia/low dysphagia; 2 - low xerostomia/high dysphagia; 3 - high xerostomia/low dysphagia; 4 - high xerostomia/ high dysphagia);

- Overall survival and disease free survival were considered equivalent with regard to radiation therapy techniques (IMRT and 3D-CRT);

- After the second year, patients remain in the same state of health until the end of life;

- It was estimated that $24 \%$ of patients would die by the end of 2 years based on the PARSPORT trial ${ }^{8}$; and

- We only considered the cost of radiation therapy. Costs related to dysphagia and xerostomia events could not be calculated.

\section{Health state utility values}

Utility values were used to quantify a patient's quality of life related to the disease burden. A utility of zero indicates patient death, while a utility of one represents a patient in full health. Utilities were used for patient health conditions, and their values were combined for dysphagia and xerostomia. The data were obtained from a quality of life study with 396 HNCPs $^{18}$ (- Supplementary material 1.).

\section{Treatment costs (IMRT and 3D-CRT)}

The 3D-CRT costs are displayed in Supplementary material 2. IMRT is not recognized or permitted in the Brazilian Public Health System. Thus, the IMRT costs for head and neck cancer were estimated based on the opinions of Brazilian Society for Radiation Oncology expert members considering the public health scenario and a relative proportion of 3D-CRT costs.

The IMRT costs were estimated based on following

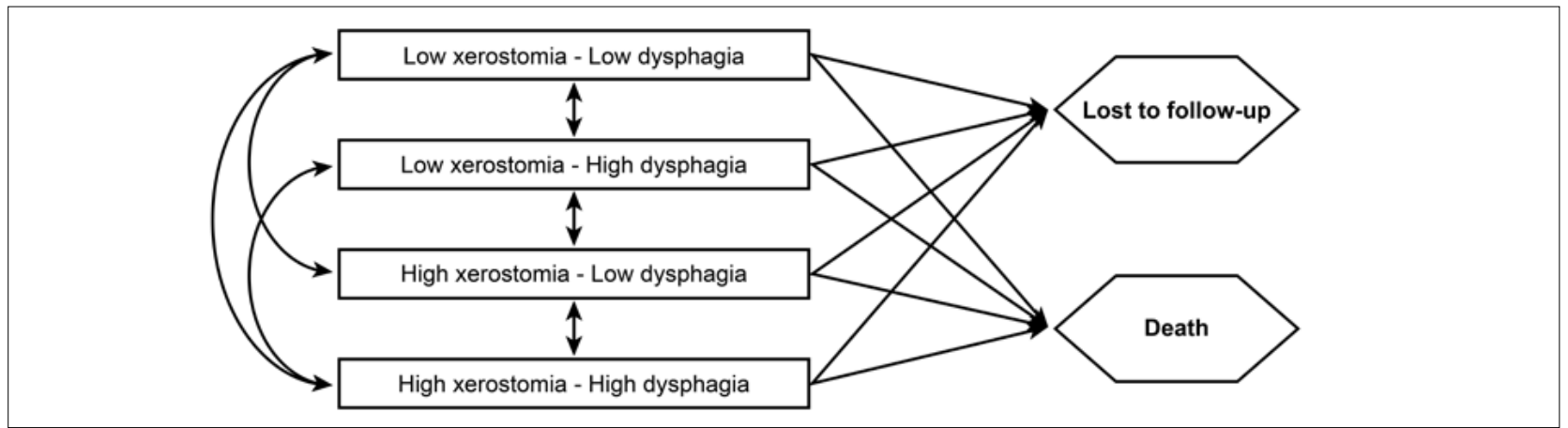

FIGURE 1 - Markov model - Health states. Representation of a Markov model for dysphagia and xerostomia progression of HNCP treated with radiation therapy. Patients might change between health states, become lost to follow-up, or die at each 6-month interval (adapted from Kohler et al. ${ }^{14}$ ). 
items: physician consult, CT simulation, IMRT mask, IMRT planning, IMRT collimator base, port film and nurse consult. A preliminary cost consult in the Brazilian private hospitals that use IMRT for the treatment of HNCPs was performed, and the costs were adapted to the Brazilian Public Health System context. The total IMRT estimated cost was BRL 10,000.

\section{Cost-effectiveness analysis}

The comparative results of treatment modalities were measured using an incremental cost-effectiveness ratio (ICER). The ICER describes the cost per QALY gained by one technique compared to another to determine the relative value. The relative value of each radiation therapy technique was calculated using the ICER. The cost-effectiveness analyses were performed in two scenarios; first, patients were followed for a period of two years (the period used by the PARSPORT trial ${ }^{8}$ ); second, patients were followed for a lifetime period (equivalent to 15 years). The projection over a horizon time of more than 2 years considered that the transition probability of death would be the same from 24 months to the end of the model. The premise of transition probabilities equal to those adopted at 24 months for the remainder of the time horizon (15 years) is based on the results of large observational studies and randomized clinical trials suggesting that after 12-18 months of follow-up, no significant improvement or worsening of the incidence of adverse events is observed ${ }^{8,19,20}$.

The World Health Organization (WHO) definition for cost-effectiveness assessment was adopted ${ }^{21}$.

\section{Sensitivity analyses}

Sensitivity analyses were performed to assess overall uncertainty in the outcomes measures. Therefore, it was possible to evaluate how the ICERs were influenced by the adopted assumptions.

Univariate and probabilistic sensitivity analyses were performed.

Univariate sensitivity analyses consider variations of a single parameter while other parameters remain constant. In this case, the critical parameters were varied from the base value to the limit values (Supplementary material 3).

Probabilistic sensitivity analyses vary several parameters simultaneously. These analyses simulate a random draw from pre-specified statistical allocations of all input parameters to create a range of potential ICER values. They were calculated with 1,000 itera- tions. The results were evaluated and classified as follows: Quadrant 1 (incremental effectiveness $>0$ and incremental cost $>0$ ); Quadrant 2 (incremental effectiveness $<0$ and incremental cost $>0$ ); Quadrant 3 (incremental effectiveness $<0$ and incremental cost $<0$ ) and Quadrant 4 (incremental effectiveness $>0$ and incremental cost $<0$ ) - Supplementary material 4 .

Health state transition probabilities were based on numerous time points of the PARSPORT trial ${ }^{8}$ (Supplementary material 5).

\section{RESULTS}

The results of the cost-effectiveness analyses are displayed in Table 1 . The patient age value was varied in the sensitivity analysis, but significant changes in the final results were not found in the base scenario.

At 2 years, IMRT was associated with an incremental benefit of 0.16 QALYs gained per person, resulting in an ICER of BRL 31,579 per QALY gained compared to 3D-CRT. IMRT was considered cost-effective when using the definition proposed by the WHO, of three times the national gross domestic product (GDP) per capita, which is equivalent to BRL 72,195.

Regarding the lifetime value, the incremental benefit of IMRT was 1.16 QALYs gained per person with an ICER of R\$4,341. IMRT was also cost-effective according to the WHO definition of a maximum cost equal to the GDP per capita, which is equivalent to BRL 24,065.

The univariate sensitivity analyses showed that the variables with the greatest effect on the results were utility low xerostomia/low dysphagia (ICER range BRL 25,418 to BRL 36,917); 3D-CRT cost (ICER range BRL 28,483 to BRL 34,674); utility high xerostomia/low dysphagia (ICER range BRL 30.733 to BRL 33.404); utility high xerostomia/high dysphagia (ICER range

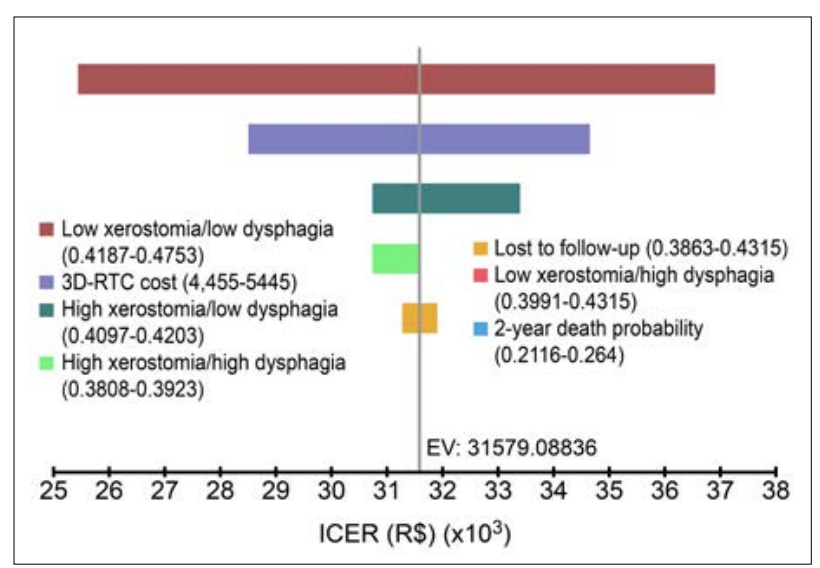

FIGURE 2 - Univariate sensitivity analyses. 
BRL 30.731 to BRL 31.579); and utility lost to follow-up (ICER range BRL 31.267 to 31.579) (Figure 2).

The probabilistic sensitivity analyses are presented in Supplementary material 6. A total of $99.1 \%$ of results remained in quadrant 1 , representing incremental results with greater effectiveness and incremental cost. In addition, approximately $90 \%$ of the iterations were below the maximum cost of BRL 72,195.

\section{DISCUSSION}

Much effort has been employed to improve HNCP outcomes, especially for locally advanced disease. Different protocols have been attempted to intensify the treatment using induction chemotherapy ${ }^{22,23}$ and/or more advanced surgical techniques ${ }^{24}$. Similarly, IMRT is an advance that has been rapidly implemented for the management of HNCPs worldwide. Based on available evidence from randomized phase III trials ${ }^{6-10}$ and a meta-analysis ${ }^{\mathbf{1 1}}$, compared to conventional radiation therapy or 3D-CRT, IMRT is associated with less toxicity and improved quality of life without compromising local control and overall survival rates. Nevertheless, this benefit might not balance the higher costs associated with IMRT ${ }^{25}$.

In the present cost-effectiveness analyses in the Brazilian Public Health System context, a Markov model was used to evaluate IMRT versus 3D-CRT. IMRT was considered cost-effective for 2 and 15 years of treatment, resulting in ICER values of BRL 31,579 and BRL 4,341 per QALY gained, respectively. These results are relevant because they demonstrate that IMRT is cost-effective during the first 2 years and after long-term follow-up. The sensitivity analyses confirmed that IMRT remains cost-effective.

Other studies have shown similar results. Yong et al. ${ }^{26}$ compared the cost-effectiveness of IMRT with 3D-CRT for the treatment of oropharyngeal tumors from the perspective of the Canadian Ministry of Health. IMRT resulted in a gain of 0.48 more QALYs at an extra cost of $\$ 2,447$, resulting in an ICER of $\$ 5,084$ per QALY gained. The number of IMRT treatments needed to avoid long-term severe xerostomia was less than 2, resulting in an incremental cost of $\$ 4,532$, which showed that compared with 3D-CRT, IMRT was cost-effective. Similarly, Kohler et al. ${ }^{17}$ performed a cost-effectiveness analysis of IMRT and 3D-CRT from the US health care cost perspective (Medicare). Less than \$50,000 per QALY gained was considered cost-effective. In the first 2 years after treatment, IMRT was not considered cost-effective (ICER of $\$ 101,100$ per QALY gained). However, over a lifetime (15 years), IMRT was considered cost-effective $(\$ 34,523$ per QALY gained). Of note, in the Yong et al. ${ }^{26}$ study, data from a nasopharyngeal trial ${ }^{6}$ were used to calculate health state utilities and simulate oropharyngeal cancer patients. Moreover, short-term transitions among toxicity health states were not assessed. Our model is similar to that used in the study by Kohler et al. ${ }^{17}$; different health states reflected diverse stages of dysphagia and xerostomia and distinguished the severity of each disease over time according to the radiation therapy techniques adopted. Thus, this model is a more complete evaluation of the value of IMRT over a range of radiation-induced side effects.

Though not directly evaluated in our study, other benefits of IMRT can result in more robust cost-effectiveness results of IMRT. The longer treatment time of IMRT with the step and shoot technique was overcome using IMRT with volumetric modulated arc therapy (VMAT) ${ }^{27}$. VMAT can minimize the radiation delivery period, resulting in a reduced treatment time. Therefore, the cost of IMRT could possibly be decreased with VMAT. Furthermore, long-term costs related to toxicities, such as extra support care and dental assistance, were not considered in our study. Decreases in long-term high-grade dysphagia and xerostomia might translate into lower toxicity-associated costs for HNCPs who receive IMRT rather than 3D-CRT. Hence, HNCPs treated with IMRT would likely have a reduced need for dental care and treatment for xerostomia and dysphagia ${ }^{28}$. This result is

TABLE 1. COST-EFFECTIVENESS ANALYSES - MARKOV MODEL

\begin{tabular}{l|c|c|c|c|c|c}
\cline { 2 - 7 } & \multicolumn{3}{c|}{2 years } & \multicolumn{3}{c}{ Lifetime (15 years) } \\
\cline { 2 - 7 } & IMRT & 3D - CRT & Incremental & IMRT & 3D - CRT & Incremental \\
\hline Cost per person (R\$) & 10,000 & 4,950 & 5,050 & 10,000 & 4,950 & 5,050 \\
\hline QALYs per person & 2.03 & 1.87 & 0.16 & 7.53 & 6.37 & 1.16 \\
\hline ICER (RS) & \multicolumn{3}{|c|}{31,579} & & 4,341
\end{tabular}

Note: IMRT = intensity modulated radiation therapy; 3D-CRT = conformal radiation therapy; ICER = incremental cost-effectiveness ratio; $Q A L Y=$ quality-adjusted life; R\$ = real. 
mainly relevant for the group of patients with a better prognosis and higher overall survival rates, such as those with human papillomavirus (HPV)-associated oropharyngeal squamous cell carcinoma ${ }^{29}$.

It is important to highlight that the costs related to dysphagia and xerostomia could not be calculated in the present study for methodological reasons. Since our analysis aimed to assess the incorporation of IMRT in the Brazilian Health System, the priority of cost estimation was given to national sources. The main source of costs for our analysis is available on DATASUS (http://datasus.saude.gov.br). The DATASUS database is used by the Brazilian Federal Government for the reimbursement of public service procedures. In this context, it is not possible to determine a causal relationship between 3D-CRT/ IMRT and a need for one of the interventions due to limitations related to patient monitoring and follow-up in the DATASUS system. The inclusion of these costs would clearly make the scenario more favorable to IMRT. However, the non-inclusion of adverse event (dysphagia and xerostomia) costs would make the scenario more conservative. Thus, this study reflected a lower probability of having an overestimated outcome in relation to the economic gains that could be achieved by IMRT incorporation into the Brazilian Health System.

One limitation of our study is that data from patients in the United Kingdom were used ${ }^{8,18}$ because data on radiation toxicities in the Brazilian population are limited. A complete study would include long-term cost and quality of life data in a study of Brazilian HNCPs receiving radiation therapy via different techniques. Hence, it is unknown whether the treatment outcomes would significantly diverge within the Brazilian population in the Public Health System context. Another limitation is that chemotherapy was not officially included in our model. It is important to recognize that our data included patients who did or did not receive concurrent chemotherapy. Therefore, the actual effect on the long-term toxicity of concurrent chemotherapy in HNCPs treated with IMRT or 3D-CRT remains unclear. The last limitation is related to the 3D-CRT and IMRT costs. All cost-effectiveness analyses were performed based on the current and outdated Brazilian Public Health System table of costs (no cost adjustments have been made since 2010). Thus, the costs of 3D-CRT and IMRT are both underestimated.

\section{CONCLUSION}

In conclusion, IMRT was considered cost-effective from the perspective of the Brazilian Public Health System. The reductions in high-grade dysphagia and xerostomia made IMRT cost-effective at two years and in the long-term. These results could help to support the implementation of IMRT in Brazilian Public Health Centers.

Conflict of Interest Statement: none to declare.

Financial disclosure: none to declare.

Authors' contributions: All authors have been involved in analysis, interpretation of data, drafting the manuscript, revising and final approval of the version to be published.

Acknowledgements: We thank the Medinsight Decisions in Health Care Company for methodological support.

\section{RESUMO}

INTRODUÇÃO: Foi realizada uma análise de custo-efetividade da radioterapia com intensidade modulada de feixe (IMRT) comparada com a radioterapia conformada para pacientes com câncer de cabeça e pescoço (CCP) no contexto do Sistema Único de Saúde (SUS).

MÉTODOS: Foi elaborado um modelo de Markov para comparar os custos médicos diretos e os desfechos de saúde relacionados à qualidade de vida do paciente pós-intervenção radioterápica sofrendo de xerostomia e disfagia. Com essa finalidade, foram usados os dados do estudo PARSPORT e parâmetros de qualidade de vida. Os resultados comparativos das estratégias alternativas de tratamento foram medidos pela razão de custo-efetividade incremental (RCEI). O desfecho analisado foi o de anos de vida ajustados à qualidade (QALY).

RESULTADOS: Em um horizonte de tempo de dois anos, a IMRT foi associada com um benefício incremental de ganho de 0,16 QALYS por indivíduo, resultando em um RCEI de R\$31.579 por QALY ganhado. A IMRT foi custo-efetivo, adotando-se o limite máximo de disposição a pagar, proposto pela OMS, de três vezes o PIB per capita nacional, equivalente a R\$ 72.195. No horizonte de tempo de 15 anos, o benefício incremental de ganho foi de 1,16 QALYs por indivíduo, com um RCEI de R\$ 4.341. A IMRT foi custo-efetivo, adotando-se o limite de disposição a pagar, proposto pela OMS, de uma vez o PIB per capita nacional, equivalente a $R \$ 24.065$.

CONCLUSÃO: A IMRT foi considerada um tratamento custo-efetivo na perspectiva do SUS.

PALAVRAS-CHAVE: Neoplasias de cabeça e pescoço. Radioterapia de intensidade modulada. Radioterapia conformada. Custo-efetividade. 


\section{REFERENCES}

1. Intensity Modulated Radiation Therapy Collaborative Working Group. Intensity-modulated radiotherapy: current status and issues of interest. Int Radiat Oncol Biol Phys. 2001;51(4):880-914.

2. Merlotti A, Alterio D, Vigna-Taglianti R, Muraglia A, Lastrucci L, Manzo R, et al; Italian Association of Radiation Oncology. Technical guidelines for head and neck cancer IMRT on behalf of the Italian association of radiation oncology - Head and Neck Working Group. Radiat Oncol. 2014;9:264.

3. Nutting CM, Convery DJ, Cosgrove VP, Rowbottom C, Vini L, Harmer C, et al. Improvements in target coverage and reduced spinal cord irradiation using intensity-modulated radiotherapy (IMRT) in patients with carcinoma of the thyroid gland. Radiother Oncol. 2001;60(2):173-80.

4. Mendez LC, Moraes FY, Poon I, Marta GN. The management of head and neck tumors with high technology radiation therapy. Expert Rev Anticancer Ther. 2016;16(1):99-110.

5. Guadagnolo BA, Liu CC, Cormier JN, Du XL. Evaluation of trends in the use of intensity-modulated radiotherapy for head and neck cancer from 2000 through 2005: socioeconomic disparity and geographic variation in a large population-based cohort. Cancer. 2010;116(14):3505-12.

6. Pow EH, Kwong DL, McMillan AS, Wong MC, Sham JS, Leung LH, et al. Xerostomia and quality of life after intensity-modulated radiotherapy vs. conventional radiotherapy for early-stage nasopharyngeal carcinoma: initial report on a randomized controlled clinical trial. Int I Radiat Oncol Biol Phys. 2006;66(4):981-91.

7. Kam MK, Leung SF, Zee B, Chau RM, Suen J), Mo F, et al. Prospective randomized study of intensity-modulated radiotherapy on salivary gland function in early-stage nasopharyngeal carcinoma patients. J Clin Oncol. 2007;25(31):4873-9.

8. Nutting CM, Morden JP, Harrington KJ, Urbano TG, Bhide SA, Clark C, et al; PARSPORT trial management group. Parotid-sparing intensity modulated versus conventional radiotherapy in head and neck cancer (PARSPORT): a phase 3 multicentre randomised controlled trial. Lancet Oncol. 2011;12(2):127-36.

9. Gupta T, Agarwal I, Jain S, Phurailatpam R, Kannan S, Ghosh-Laskar S, et al. Three-dimensional conformal radiotherapy (3D-CRT) versus intensity modulated radiation therapy (IMRT) in squamous cell carcinoma of the head and neck: a randomized controlled trial. Radiother Oncol. 2012;104(3):343-8

10. Peng G, Wang T, Yang KY, Zhang S, Zhang T, Li Q, et al. A prospective, randomized study comparing outcomes and toxicities of intensity-modulated radiotherapy vs. conventional two-dimensional radiotherapy for the treatment of nasopharyngeal carcinoma. Radiother Oncol. 2012;104(3):286-93.

11. Marta GN, Silva V, Andrade Carvalho H, Arruda FF, Hanna SA, Gadia R, et al. Intensity-modulated radiation therapy for head and neck cancer: systematic review and meta-analysis. Radiother Oncol. 2014;110(1):9-15.

12. Van Rij CM, Oughlane-Heemsbergen WD, Ackerstaff AH, Lamers EA Balm AJ, Rasch CR. Parotid gland sparing IMRT for head and neck cancer improves xerostomia related quality of life. Radiat Oncol. 2008;3:41.

13. Peponi E, Glanzmann C, Willi B, Huber G, Studer G. Dysphagia in head and neck cancer patients following intensity modulated radiotherapy (IMRT). Radiat Oncol. 2011;6:1.

14. Miles EA, Clark CH, Urbano MT, Bidmead M, Dearnaley DP, Harrington $\mathrm{K}$, et al. The impact of introducing intensity modulated radiotherapy into routine clinical practice. Radiother Oncol. 2005;77(3):241-6.

15. Van de Werf E, Lievens $Y$, Verstraete J, Pauwels K, Van den Bogaert W. Time and motion study of radiotherapy delivery: economic burden of increased quality assurance and IMRT. Radiother Oncol. 2009;93(1):137-40.
16. Moraes FY, Marta GN, Hanna SA, Leite ET, Ferrigno R, Silva JL, et al. Brazil's challenges and opportunities. Int | Radiat Oncol Biol Phys. 2015;92(4):707-12.

17. Kohler RE, Sheets NC, Wheeler SB, Nutting C, Hall E, Chera BS. Two-year and lifetime cost-effectiveness of intensity modulated radiation therapy versus 3-dimensional conformal radiation therapy for head-and-neck cancer. Int J Radiat Oncol Biol Phys. 2013;87(4):683-9.

18. Ramaekers BL, Joore MA, Grutters |P, van den Ende P, Jong |, Houben R, et al. The impact of late treatment-toxicity on generic health-related quality of life in head and neck cancer patients after radiotherapy. Oral Oncol. 2011;47(8):768-74.

19. Schoenfeld GO, Amdur RJ, Morris CG, Li JG, Hinerman RW, Mendenhall WM. Patterns of failure and toxicity after intensity-modulated radiotherapy for head and neck cancer. Int | Radiat Oncol Biol Phys. 2008;71(2):377-85.

20. Eisbruch A, Harris I, Garden AS, Chao CK, Straube W, Harari PM, et al. Multi-institutional trial of accelerated hypofractionated intensity-modulated radiation therapy for early-stage oropharyngeal cancer (RTOG 0022). Int J Radiat Oncol Biol Phys. 2010;76(5):1333-8.

21. World Health Organization. WHO guide to cost-effectiveness analysis. [cited 2014 Sep 9]. Available from: www.who.int/choice/publications/p_2003_generalised_cea.pdf

22. Marta GN, William WN Jr, Feher O, Carvalho AL, Kowalski LP. Induction chemotherapy for oral cavity cancer patients: current status and future perspectives. Oral Oncol. 2015;51(12):1069-75.

23. Marta GN, Riera R, Bossi P, Zhong LP, Licitra L, Macedo CR, et al. Induction chemotherapy prior to surgery with or without postoperative radiotherapy for oral cavity cancer patients: systematic review and meta-analysis. Eur J Cancer. 2015;51(17):2596-603.

24. Lee HS, Kim D, Lee SY, Byeon HK, Kim WS, Hong H], et al. Robot-assisted versus endoscopic submandibular gland resection via retroauricular approach: a prospective nonrandomized study. Br f Oral Maxillofac Surg. 2014:52(2):179-84.

25. Sheets NC, Wheeler SB, Kohler RE, Fried DV, Brown PM, Chera BS. Costs of care in a matched pair comparison of intensity-modulated radiation therapy (IMRT) versus conventional radiation therapy (CRT) for the treatment of head and neck cancer. Am J Clin Oncol. 2014;37(6):539-44

26. Yong JH, Beca J, O'Sullivan B, Huang SH, McGowan T, Warde P, et al. Cost-effectiveness of intensity-modulated radiotherapy in oropharyngeal cancer. Clin Oncol (R Coll Radiol). 2012;24(7):532-8.

27. MacFarlane M, Hoover DA, Wong E, Read N, Palma D, Venkatesan V, et al. Evaluation of unified intensity-modulated arc therapy for the radiotherapy of head-and-neck cancer. Radiother Oncol. 2016;119(2):331-6.

28. Jensen SB, Pedersen AM, Vissink A, Andersen E, Brown CG, Davies AN, et al; Salivary Gland Hypofunction/Xerostomia Section; Oral Care Study Group; Multinational Association of Supportive Care in Cancer (MASCC)/International Society of Oral Oncology (ISOO). A systematic review of salivary gland hypofunction and xerostomia induced by cancer therapies: management strategies and economic impact. Support Care Cancer. 2010;18(8):1061-79.

29. O'Sullivan B, Huang SH, Su J, Garden AS, Sturgis EM, Dahlstrom K, et al. Development and validation of a staging system for HPV-related oropharyngeal cancer by the International Collaboration on Oropharyngeal cancer Network for Staging (ICON-S): a multicentre cohort study. Lancet Oncol. 2016;17(4):440-51. 